\title{
Academic top earners. Research productivity, prestige generation, and salary patterns in European universities
}

\section{Marek Kwiek*}

Center for Public Policy Studies, Director, UNESCO Chair in Institutional Research and Higher Education Policy, University of Poznan, ul. Szamarzewskiego 89, 60-569 Poznan, Poland

*Corresponding author. Email: kwiekm@amu.edu.pl

\begin{abstract}
This article examines highly paid academics—or top earners-employed across universities in ten European countries based on large-scale international survey data regarding the academic profession. It examines the relationships between salaries and academic behaviors and productivity, as well as the predictors of becoming an academic top earner. While, in the Anglo-Saxon countries, the university research mission typically pays off at an individual level, in Continental Europe, it pays off only in combination with administrative and related duties. Seeking future financial rewards solely through research does not seem to be a viable strategy in Europe, but seeking satisfaction in research through solving research puzzles is also becoming difficult, with the growing emphasis on the 'relevance' and 'applicability' of fundable research. Thus, both the traditional 'investment motivation' and 'consumption motivation' to perform research decrease, creating severe policy implications. The primary data come from 8,466 usable cases.
\end{abstract}

Key words: academic salaries; highly paid academics; European universities; working time distribution; research productivity; predictors of academic incomes.

\section{Introduction}

This research examines an emergent class of highly paid academics—or top earners-employed across European universities. It differs from existing salary studies in its focus, sample, and method. It goes beyond previous work that has studied academic salaries either in single institutions (Katz 1973; Ferber 1974; Fox 1985), multiple institutions (Hamermesh et al. 1982; Konrad and Pfeffer 1990; Ward 2001) or national systems (mostly the USA, as in McLaughlin et al. (1979); Gomez-Mejia and Balkin (1992); Bellas (1993); Fairweather (1993); Barbezat and Hughes (2005); Fairweather (2005); Melguizo and Strober (2007)). Also, it explores crossnational differences in salary patterns in ten European countries based on large-scale international survey data regarding the academic profession $(N=17,211)$. This research also goes beyond a more traditional approach, which examines the relationships between academic salary and its correlates through only bivariate correlational analyses, by using both logistic regression analyses and bivariate correlational analyses. This research examines the relationships between academic salaries and academic behaviors and productivity in a single institutional type, the European university, exploring one subcategory of academics: academics employed full-time and involved in both teaching and research. Finally, this article explores predictors of becoming an academic top earner from a comparative cross-national European perspective.

The massification of higher education inevitably leads to the massification of the academic profession, with dramatic consequences in terms of its social and financial standing. As a global collection of 28 country studies emphasized, 'without conditions that permit a secure career, competitive with alternatives in the labor market, the entire academic enterprise will falter' (Altbach et al. 2012: 3). Even though salaries are only a single element in a larger picture of the academic research environment, it is a highly important element and a major component of institutional budgets. For a long time, academic salaries have been under-valued as a research topic and, consequently, largely under-researched in higher education studies. However, in the last two decades, academic salary studies have been booming, with more than a hundred publications. The financial instability of the academic profession as part of the traditional core component of the middle classes across developed countries has helped to drive this research. However, there are only a few cross-national comparative salary studies focusing on more than two countries (Shen and Xiong (2015); see also reports based largely on descriptive statistics: Idea Consult 2013, 
produced within the MORE 2 project; European Commission 2007 on salaries in academia and industry; Deloitte 2012 on salaries in Anglo-Saxon countries; and European Commission and Deloitte 2014 on working conditions and salaries across Europe), in addition to two collections of national case studies (Rumbley et al. 2008; Altbach et al. 2012).

We use two complementary approaches: statistical inference ( $t$-tests for the equality of means performed on two independent samples of academic top earners, defined as the upper 20 percent of academics on the academic income scales on disciplinary and national bases as compared to the rest of academics, with these $t$-tests being applied to various aspects of working time distribution and research productivity, Section 4.1) and a multidimensional logistic regression model (Section 4.2). While most previous studies rely on linear regression models, this research relies on a logistic regression model in seeking country-specific predictors of becoming a highly paid academic across Europe. The primary data analyzed come from two large-scale global and European research projects on the academic profession, CAP: Changing Academic Profession and EUROAC: Academic Profession in Europe, with 8,466 usable cases for our purposes. The data refer to highly paid academics (the upper 20 percent, $N=649$ ), who are contrasted with the remaining 80 percent of academics $(N=2,937)$; in both cases, the term 'academics' refers only to those who are employed full-time in the university sector, indicate both teaching and research involvement and provide income data.

\section{Analytical framework}

\subsection{Differences in salary regimes}

The reward structure in science consists of two components (Stephan 2010). First, science is governed by the priority system, a reward system that encourages the production and sharing of knowledge. Scientists are motivated to perform research 'by a desire to establish priority of discovery' (Stephan 2010: 2) because recognition in science depends on 'being first' (Stephan 1996: 1202). Also, second, the reward structure in science consists of remuneration. Academic positions provide both extrinsic rewards (salaries and other material benefits) and intrinsic rewards (derived from academic work) (Blau 1994; Stern 2004). Poor salaries are a major impediment to effective faculty recruitment. National academic labor markets (Williams et al. 1974; Fairweather 1995) determine who academics are and who they will become in the future. They produce or fail to produce the requisite talent in academe.

Institutions with more open salary systems, notably in the USA, are more able to attract top-quality researchers from institutions with less open salary systems, notably those in Continental Europe. Academics across large parts of Continental Europe are still typically civil servants paid largely based on a single well-defined fixed-salary system (Altbach et al. 2012). Consequently, 'universities in the US have greater leeway than those in most other places to reward performance and to pay high salaries to attract star researchers' (Stephan 2012: 1). However, in the last two decades, most European systems have tended to introduce various forms of merit pay, moving very slowly away from fixed-salary systems (Enders and de Weert 2004: 18-19; and national case studies in Altbach et al. 2012).

\subsection{Models of academic salaries}

Existing theories of faculty pay can be categorized into market models and institutional models, which view academic pay as a function of either market competition or institutional forces, respectively
(Fairweather 2005: 403). Two market models attribute changes in faculty salaries, at least in part, to changes in supply and demand: one school emphasizes the homogeneity of national academic markets based on research and prestige (research output is highly valued in research-oriented institutions, and top research performers are paid more), and the other school emphasizes the segmented character of national academic markets (teaching-oriented institutions value teaching over research, and top teachers are paid more). The institutional theories of faculty pay emphasize that pay is an expression of institutional norms and values, regardless of institutional missions, and that institutional forces can dictate salary levels: 'institutions that actually value teaching will pay their productive teachers the most, whereas institutions valuing research will pay their productive researchers the most' (Fairweather 2005: 403). In a standard human capital model (as used by Hamermesh et al. (1982)), academic earnings are a function of research productivity (on the demand side), as well as any factors that affect the equilibrium supply of labor. Faculty salary is also viewed as indirectly related to productivity because more productive academics are likely to be promoted faster and promotions mean higher financial rewards.

Scientists' engagement in research can be either investmentmotivated (seeking future financial rewards), consumptionmotivated (seeking research puzzles) or both (Thursby et al. 2007). While the investment motive implies a decline in research productivity over one's career, the consumption motive does not imply such a decline (Levin and Stephan 1991). A 'taste for science' (Roach and Sauermann 2010)—-that is, for nonpecuniary returns—causes scientists to choose academia over industry. Academics with different abilities and tastes in terms of nonpecuniary returns choose different careers: basic or applied research in academia or industry (Agarwal and Ohyama 2012). Time spent on research reduces current earnings but increases future earnings, as in investment models of human capital. On average, scientists become less productive as they age (Over 1982; Kyvik 1990; Levin and Stephan 1991; Stephan and Levin 1992), with changing research productivity over the lifecycle and productivity in systems with aging academic cohorts being important research focuses.

From the perspective of the economics of higher education, specifically the concepts of labor economics, academic compensation is influenced by a number of factors related to the demand for higher education services and the supply of qualified individuals for faculty positions (Toutkoushian and Paulsen 2016: 324). From this perspective, academics have acquired human capital (skills and talents that an individual can obtain through education, training and experience in the labor market) and endowed human capital (natural ability and talent) (Toutkoushian and Paulsen 2016: 351). In academic labor markets, academics can have large variations in their levels of both types of human capital. The connection between human capital and academic salaries follows from the effects of human capital on productivity, which in turn influences pay (Toutkoushian and Paulsen 2016: 353). As Toutkoushian and Paulsen point out, 'if faculty compensation is determined in part by an individual's productivity in teaching, research, and public service, then salaries should be correlated with productivity. Human capital theory would thus predict that faculty with more acquired and endowed human capital would, on average, have higher salaries than other faculty' (2016: 353).

Economic models of academic salary determination have been predominantly based on the human capital theory (embedded in analyses of for-profit firms and treating higher education institutions accordingly); in the prestige model of salary determination, 
universities behave as both firms and nonprofit institutions, or 'hybrids' (Melguizo and Strober 2007: 634). In the prestige model, academic salaries are viewed as returns on the generation of prestige (for the individual academic, as well as the institution). Nonprofit higher education institutions act largely as 'prestige maximizers', just like for-profit companies act as 'profit maximizers': 'not only are institutions seeking to maximize prestige, so are departments and faculty members' (Melguizo and Strober 2007: 635). While human capital salary models focus on individuals' research, teaching and public service productivity, a potential alternative model focuses on individuals' prestige generation, mostly through publications, research grants, patents and awards, that is, productivity. Both the human capital model and the prestige model state that higher productivity (defined for different areas, with publications being at the forefront) should lead to higher academic incomes.

Prestige is largely a rival good, based on relative, rather than absolute, measurement, and accumulating prestige is a zero-sum game (Brewer et al. 2002: 30). Academia is becoming ever more competitive, and competitiveness is encouraged by deliberate government policies: 'at the centre of all this is prestige, at all levels from the national system to the individual' (Blackmore 2016: 1). Universitiesas well as academics-compete in prestige markets. In particular, there is a strong link between individual and institutional prestige: 'in maximizing their individual prestige, faculty members simultaneously maximize the prestige of their departments and institutions' (Melguizo and Strober 2007: 635).

The maximization of prestige, in this theoretical framework, is strongly correlated with faculty salaries. Academics who help their institution to become prestigious are rewarded by the institution with higher salaries: more articles and books published in prestigious outlets, more prestigious research grants, more patents, etc. lead to higher institutional prestige, which consequently, albeit not directly, leads to higher individual salaries. That is, 'the currency in which institutions are paid for faculty research is prestige. As a result, institutions provide financial rewards to scholarly output', with faculty salaries being viewed as returns on the generation of prestige (Melguizo and Strober 2007: 639).

Following the logic of this salary model, in the context of our research, highly productive academics should be disproportionately overrepresented among highly paid academics. Because more time spent on teaching means less time spent on research and vice versa, or there being only 'research' and 'non-research' time investments (Levin and Stephan 1991: 115), academics spending, on average, more time on research should be receiving higher average salaries. Spending more time on teaching, in turn, should have a negative or, at best, neutral effect on one's salary (Katz 1973; Dillon and Marsh 1981; Konrad and Pfeffer 1990; Fairweather 1993). However, there is a difference between spending time on research, being research-focused, and being highly productive as compared with one's peers: highly productive academics can also have more formal responsibilities as leaders, deans, heads of departments, etc. and still have coauthored publications with their post-docs or other early-stage researchers. The chance to have longer lists of coauthored publications may increase for selected academics with more institutional power, and institutional power increases with age and seniority (Stephan and Levin 1992).

\section{Data and methods}

The data for this research project were collected from 2007 to 2010 through a survey administered in eleven European countries; however, income data were only available in the following ten countries: Austria, Finland, Germany, Italy, the Netherlands, Norway, Poland, Portugal, Switzerland, and the UK. The survey (conducted within two large-scale research projects: CAP 'Changing Academic Profession' and EUROAC 'Academic Profession in Europe: Responses to Societal Challenges') has been widely used in higher education research; however, to date, academic incomes have not been explored in detail based on this survey (except for Shen and Xiong (2015), which is mostly descriptive, and Nanbu and Amano (2015) for a single-nation research, Japan). The eleven national datasets were cleaned, weighted, and merged into a single European dataset, which is now the most comprehensive crossnational source of data on academic views, attitudes, perceptions, and behaviors in Europe. The author acted as a Principal Investigator in Poland. The total number of usable returned surveys in Europe was 17,211 and included between 1,000 and 1,700 returned surveys from all the countries studied, except for Poland, where the total number of responses was higher. The overall quality of the dataset is high (Teichler et al. 2013: 35; Teichler and Höhle 2013: 9).

In technical terms, we divided the sample of all academics who reported their incomes (as elsewhere throughout the article, only those employed full-time in the university sector) in the ten abovementioned countries into academic 'top earners' and 'the rest'. Top earners are defined as those in the 80th percentile of gross academic income-the upper 20 percent of academics in each of the five major clusters of academic fields (separately), in each country (separately), cut-off points permitting. We did not want to combine all full-time academics from the university sector into a single subset, because the vast majority of top earners would then come from Switzerland and none would come from Poland or Portugal (based on the nominal values of their salaries). We also wanted to explore all the systems and examine national-level top earners cross-nationally.

Additionally, we restricted our subsample of top earners and the rest: we have explored only academics who are at least 40 years old and have at least 10 years of academic experience. This was done to avoid comparing academics across radically different age cohorts with different seniority levels and, especially, different job characteristics. Analyzing top earners and the rest of academics across all age cohorts and all career stages and seniority levels would significantly increase the number of observations but would also lead to potentially erroneous results with regard to the time spent on research. Analyzing only older academics with longer academic experience (longer time passed since first full-time employment) leads to more robust results. However, this is the second-best approach, the best approach being a study of smaller age cohorts and seniority and career-stage cohorts separately, which is not possible due to the radically decreased numbers of observations by country and academic discipline cluster in such a case. In a lifecycle view, faculty devote more time to research early in their careers and less time to research later on (see, e.g. Thursby et al. 2007; Levin and Stephan 1991). In the US context, achieving tenure is a critical point, as is a Habilitation degree (a postdoctoral degree that exists in various versions) in a number of European systems, including the majority in our sample: Germany, Poland, Finland, Switzerland, Austria, Portugal, and Italy. Consequently, in Europe, academics aged 40 years and over are already a relatively homogenous cohort. 'The rest' of academics is defined here as the remaining 80 percent of academics who are at least 40 years old and have at least 10 years of academic experience.

The entire sample includes 17,211 cases, and the number of valid cases with income and disciplinary data in the selected cohort is 3,586 , including both top earners $(N(\mathrm{TE})=649$, or 18.1 percent $)$ and 
Table 1. Sample description: frequencies of selected demographic characteristics, all countries combined.

\begin{tabular}{|c|c|c|c|}
\hline & & $\begin{array}{l}\text { Full-time employed in } \\
\text { the university sector, involved in } \\
\text { both teaching and research } \\
\text { (all responses) } \\
\mathrm{N}(\%)\end{array}$ & $\begin{array}{c}\text { Full-time employed in the } \\
\text { university sector, involved in } \\
\text { both teaching and research } \\
\text { (responses with valid income data) } \\
\mathrm{N}(\%)\end{array}$ \\
\hline \multirow[t]{2}{*}{ Gender } & Male & $3,174(65.9)$ & $2,488(66.9)$ \\
\hline & Female & $1,639(34.1)$ & $1,230(33.1)$ \\
\hline \multirow[t]{5}{*}{ Age (years) } & $40-44$ & $1,035(21.4)$ & $796(21.3)$ \\
\hline & $45-49$ & $1,098(22.7)$ & $789(21.2)$ \\
\hline & $50-54$ & $754(15.6)$ & $599(16.1)$ \\
\hline & $55-59$ & $938(19.4)$ & $723(19.4)$ \\
\hline & $\geq 60$ & $1,011(20.9)$ & $825(22.1)$ \\
\hline \multirow[t]{3}{*}{ Academic experience $^{a}$ (years) } & $10-19$ & $1,527(41.3)$ & $1,188(39.6)$ \\
\hline & $20-29$ & $1,176(31.8)$ & $958(32.0)$ \\
\hline & $\geq 30$ & $992(26.8)$ & $852(28.4)$ \\
\hline \multirow[t]{2}{*}{ Clusters of academic fields ${ }^{\mathrm{b}}$} & Hard sciences & $2,558(55.5)$ & $2,031(56.6)$ \\
\hline & Soft sciences & $2,051(44.5)$ & $1,554(43.4)$ \\
\hline
\end{tabular}

${ }^{a}$ A cluster of 'hard sciences' includes 'physical sciences and mathematics', 'life sciences and medical sciences', and 'engineering', a cluster of 'soft sciences' includes 'humanities and social sciences' and 'professions' (Question A2).

b'Academic experience' means the number of years since first full-time employment ('beyond research and teaching assistant in higher education/research sector', Question A6).

the rest of academics $(N(R)=2,937$, or 81.9 percent) (see Table 8 in the Supplementary Material). About two-thirds of academics in the sample are male, with the age cohorts for academics aged at least 40 years and academic experience cohorts being relatively evenly distributed. The distribution of the sample population by country and the frequencies of selected demographic characteristics are shown in Table 1 (all academics) and Table 2 (top earners only). Table 9 in the Supplementary Material provides data on the nonresponse rate pertaining to the gross annual salary question, which ranged from as low as 0.6 percent in the UK and 1.1 percent in Poland to as high as 31.2 percent in Switzerland and 47.4 percent in Austria.

\subsection{Limitations of this research}

The results of this research should be interpreted in light of several limitations, specifically those related to the sample, methods, procedures, and dataset. First, while this research goes beyond the limitation of being a single-institution study, as is the case with the majority of papers on academic incomes published in the last four decades, and thus it is not a case study, the national-level sampling techniques differed across the ten countries studied (see Teichler and Höhle (2013: 6-9); and RIHE (2008: 89-178)), as did the ways in which the survey questionnaire was distributed (paper, on-line, or combined), the response rates, the distribution of academics across various institutional types and various forms of employment, etc. These could have influenced the final results. Second, the analyses are based on self-declared data that were provided by academics voluntarily, with some items potentially being viewed as more sensitive in some countries than in others (e.g. income and research productivity). Specifically, the analyses are based on self-reported annual gross income, and there are substantial differences between taxation systems across Europe, with the same gross income leading to vastly different net incomes.

Third, we use a rather crude measure of research productivity, which is defined as the number of peer-reviewed articles published in a 3 -year reference period. The survey does not allow an examination of journal quality (and especially does not allow to a distinction between top-tier journals and others) or the examination of
Table 2. Sample description: frequencies of selected demographic characteristics, all ten countries combined, top earners only.

\begin{tabular}{llc}
\hline & & $N(\%)$ \\
\hline Gender & Male & $489(82.8)$ \\
Age (years) & Female & $102(17.2)$ \\
& $40-44$ & $44(7.4)$ \\
& $45-49$ & $87(14.7)$ \\
& $50-54$ & $88(14.8)$ \\
Academic experience $^{\text {a }}$ (years) & $55-59$ & $146(24.5)$ \\
& $\geq 60$ & $230(38.6)$ \\
& $10-19$ & $127(23.2)$ \\
Clusters of academic fields $^{b}$ & $20-29$ & $179(32.7)$ \\
& $\geq 30$ & $241(44.1)$ \\
& Hard sciences & $346(58.1)$ \\
& Soft sciences & $249(41.9)$
\end{tabular}

a A cluster of 'hard sciences' includes 'physical sciences and mathematics', 'life sciences and medical sciences', and 'engineering', a cluster of 'soft sciences' includes 'humanities and social sciences' and 'professions' (Question A2).

b'Academic experience' means the number of years since first full-time employment ('beyond research and teaching assistant in higher education/research sector', Question A6).

citation counts. However, to strengthen the robustness of our productivity analyses, we have used three fractionalized versions of the dependent variable: peer-reviewed article equivalents (also capturing authored and edited books), internationally coauthored article equivalents, and foreign language (here, English) article equivalents. We were unable to examine individual academics' research outputs and link them to institutional tiers based on national prestige ladders in the ten countries, rather than merely linking them to institutional types (such as 'universities' in out case, as opposed to 'polytechnics' and 'other'). We were also unable to define the selectivity of the employing institution (and of the $\mathrm{PhD}$ graduation institution) or its wealth, size or current national or international ranking. Finally, with the dataset in question, we were also unable to study how patterns of academic salaries change over time intra-nationally and cross-nationally. 
On top of these specific limitations, more generic limitations linked to cross-country comparisons in higher education in general, given the differences in academic traditions across national systems, must be mentioned. Comparative higher education has its potentials, as well as its limits (Teichler 1996; Altbach 2002), and moving from single-nation studies to cross-national studies, which involves the emergence of international datasets and the institutionalization of cross-national research, introduces new challenges. Analytical frameworks in higher education research have mostly been produced for national, rather than cross-national, interpretive purposes. The knowledge base for cross-national studies increases (and the CAP/ EUROAC dataset used here provides a new type of comparative data: primary, disaggregated and self-produced by researchers, rather than the secondary, national-level, aggregated data commonly collected by the state), but international comparative research in higher education is seldom grounded in ideal research designs with clearly defined hypotheses. Datasets such as ours are clearly produced in heterogeneous national higher education settings: national academic traditions lead to strong differences in national career opportunities, research funding availability, dominant missions in various institutional types, dominant academic activities in various system subsectors, preferred academic role orientations, favored publication outlets, etc. The meanings of such basic terms as, e.g., 'professor', 'young academic', 'competitive research funding' and 'academic duties' differ from country to country and must still be translated into a common set of concepts to organize data analysis. Consequently, the best approach is to use a semi-structured research design that reflects the wealth of options in higher education (with enough room for the application of internationally incompatible variables; in the EUROAC project, 480 interviews were conducted across seven European countries, but the qualitative material is not used in this research project). All in all, however, despite inherent limitations, cross-national studies of the academic profession create new insights with interesting institutional policy and national policy implications.

\section{Results}

\subsection{Bivariate analysis: academic top earners vs. the rest of academics}

In this section, we explore differences in working time distribution and productivity differentials between academic top earners and the rest of academics, specifically among older (aged 40 years and more) and more academically experienced (10 or more years since the first employment) cohorts to avoid the exploration of groups of academics with significantly different job profiles.

\subsubsection{Bivariate analysis: academic income and working time distribution}

Here, we explore five dimensions of academic work that were captured by the CAP/EUROAC dataset: teaching, research, service, administration, and other academic activities. We focus on weekly hours in the teaching periods of the academic year, as well as in its nonteaching periods. We annualize these hours, assuming that 60 percent for the former period and 40 percent for the latter period represents a good approximation for the majority of the ten European systems studied (regarding the average length of the teaching and nonteaching periods during an academic year across Europe, see Bentley and Kyvik (2013), who use a similar 66.6/33.3 ratio in a global study of thirteen countries). We explore the differences in the means of various categories of working hours (by academic activity) between the two subpopulations in each country (Table 3). Our results are based on two-sided tests assuming equal differences in arithmetic means with a significance level of $\alpha=0.05$. For each pair with a mean difference significantly different from zero, the symbol of the larger category ('Top' for top earners and 'Rest' for the rest of academics) appears in the column. Tests are adjusted for all pairwise comparisons within a row for each innermost subtable using the Bonferroni correction. $T$-tests for the equality of two arithmetic means ('Top' vs. 'Rest') were performed for each country for each of the five types of academic activities studied, as well as for total working hours.

Previous studies on academic salaries have strongly suggested that longer research hours contribute strongly to higher salaries (e.g. Katz 1973; Hamermesh et al. 1982; Fairweather 2005): our study shows that while top earners in three European countries indeed work statistically significantly longer 'total hours', most importantly, in six countries, they work longer 'service' (four countries) and/or 'administration' hours (four countries; see either 'Rest' or 'Top' symbols for each country).

Interestingly, statistically significant working time differentials between top earners and the rest of academics do not exist for teaching and research time investments, except in the UK, where there is clearly a different pattern: top earners, on average, spend more than 6.5 hours more per week on research, and the rest of academics spend, on average, more than 5 hours more on teaching (see Table 10 in the Supplementary Material for details). Previous research findings generally showed a strong positive correlation between research hours and salary levels and also a negative or no correlation between teaching hours and salary levels (Katz 1973; Dillon and Marsh 1981; Hamermesh et al. 1982; Konrad and Pfeffer 1990; Fairweather 2005; Melguizo and Strober 2007). Our research on the European sample does not confirm these findings. The traditional link between higher time investments in research and higher incomes-consistently demonstrated (mostly for Anglo-Saxon countries, especially the USA) in the last half a century-does not currently seem to hold across Continental Europe. Interestingly, from the perspective of future academic careers, top earners tend to spend more time (than the rest of academics) on all academic activities except for teaching and research, and they especially spend more time on administration and service. There is one qualification, however: the time measured is the current time, not the time spent a decade earlier, which may have led to their current positions.

Table 3. Working hours differentials. Results of $t$-tests for the equality of means, top earners (Top) vs. the rest of academics (Rest), in ten countries. Question B1: 'Considering all your professional work, how many hours do you spend in a typical week on each of the following activities'? (when 'classes are in session' and when 'classes are not in session'), only academics employed full-time in universities and involved in both teaching and research (annualized mean weekly hours).

\begin{tabular}{|c|c|c|c|c|c|c|c|c|c|c|}
\hline & PL & $\mathrm{DE}$ & $\mathrm{AT}$ & FI & IT & NL & $\mathrm{NO}$ & PT & $\mathrm{CH}$ & UK \\
\hline Teaching hours & & & & & & & & & & Rest \\
\hline Research hours & & & & & & & & & & Top \\
\hline Service hours & Top & & & & & Top & Top & & Top & \\
\hline $\begin{array}{l}\text { Administration } \\
\text { hours }\end{array}$ & Top & Top & & Top & & & Top & & & \\
\hline Other hours & & Top & & & & & Top & & & \\
\hline Total hours & & Top & & Top & & & & & Top & \\
\hline
\end{tabular}




\subsubsection{Bivariate analysis: academic income and research productivity}

The analysis of individual research productivity involves three measures: 'peer-reviewed article equivalents' (PRAE), 'internationally coauthored article equivalents' (ICAE), and 'English language article equivalents' (EAE). The PRAE measure is calculated (following Bentley (2015)) as the weighted sum of self-reported articles in books or journals ( 1 point), edited books ( 2 points) and authored books ( 5 points) published over the period of 3 years prior to the survey execution. An individually provided share of peer-reviewed publications is applied to each observation. The PRAE measure captures publishing through various outlets and does not focus only on articles, leaving room for authored books and edited books, which are still a major outlet in the social sciences and humanities in some European systems. The ICAE measure applies the individually provided share of publications coauthored with international colleagues, and the EAE measure applies the individually-provided

Table 4. Research productivity and high academic income, summary. Results of $t$-tests for the equality of means, top earners (Top) vs. the rest of academics (Rest) in ten countries. Group with a significantly larger mean (Top or Rest) shown by country. Question D4/3: 'How many of the following scholarly contributions have you completed in the past three years?' combined with Question D5: 'Which percentage of your publications in the last three years were - peer-reviewed' (PRAE), 'were - published in a language different from the language of instruction at your current institution' (EAE), and 'were - co-authored with colleagues located in other (foreign) countries' (ICAE): 'Articles published in an academic book or journal', 'Scholarly books you authored or co-authored' and 'Scholarly books you edited or co-edited'. Only full-time academics employed in universities and involved in both teaching and research.

\begin{tabular}{|c|c|c|c|c|}
\hline & PL DE & Г FI IT & NL NO PT & H UK \\
\hline $\begin{array}{r}\text { Peer-reviewed article } \\
\text { equivalent (PRAE) }\end{array}$ & Top Top & Top Top & Top Top & Top \\
\hline $\begin{array}{l}\text { Internationally } \\
\text { coauthored article } \\
\text { equivalent (ICAE) }\end{array}$ & Top Top & Top & Top & Top \\
\hline $\begin{array}{l}\text { Foreign language article } \\
\text { equivalent (EAE) }\end{array}$ & Top Top & Top Top & Top Top & \\
\hline
\end{tabular}

share of publications published in a foreign language (assuming that the language in question in all countries, except for the UK, is predominantly English, as descriptive statistics shows). In the majority of the countries studied (for Austria, the Netherlands and Switzerland, there are no statistically significant results), top earners are, on average, much more academically productive in the threeyear reference period (see 'Top' in all lines in Table 4).

The productivity differential between top earners and the rest of academics, as defined in this article, is high and statistically significant, mostly at a high level $(\mathrm{P}<0.001)$, especially in the case of peer-reviewed article equivalents. In seven countries-Poland, Germany, Finland, Italy, Norway, Portugal and the UK- it is, on average, in the $80-140$ percent range. Only in Italy is the differential lower, at 43 percent (the reason could be that Italian academics show the highest average individual productivity among the European countries studied; see Kwiek (2015a; 2016a)). For instance, in the UK, the average number of peer-reviewed article equivalents published in the 3 -year reference period by the rest of academics is 4.63 , while the equivalent number for top earners is 11.3 , or 144.06 percent more. In the case of internationally coauthored article equivalents, the difference is even higher: 180.49 percent for Poland, 178.05 percent for the UK, 145.56 percent for Germany and 100 percent for Finland (the 95 percent confidence interval for the difference of means and other statistical details are provided in Table 11 in the Supplementary Material).

Our analysis shows (see graphically Figs 1 and 2) that the upper 20 percent of academics in terms of incomes (or our 'top earners') in the majority of countries studied are substantially more productive and produce much more internationally coauthored publications than the rest of academics (from the same older age cohort). While they work on average longer 'administrative' and 'service' hours (rather than research hours), they are much more academically productive.

Is higher academic income positively correlated with better research performance, even though it does not seem to be positively correlated with research time investments? Are top earners disproportionately represented among top research performers (defined here in a similar manner as top earners, as academics located in the upper 20 percent of research productivity, a pool created separately for major academic disciplines and for each country and then merged; regarding predictors of becoming 'top research performers' across Europe, see

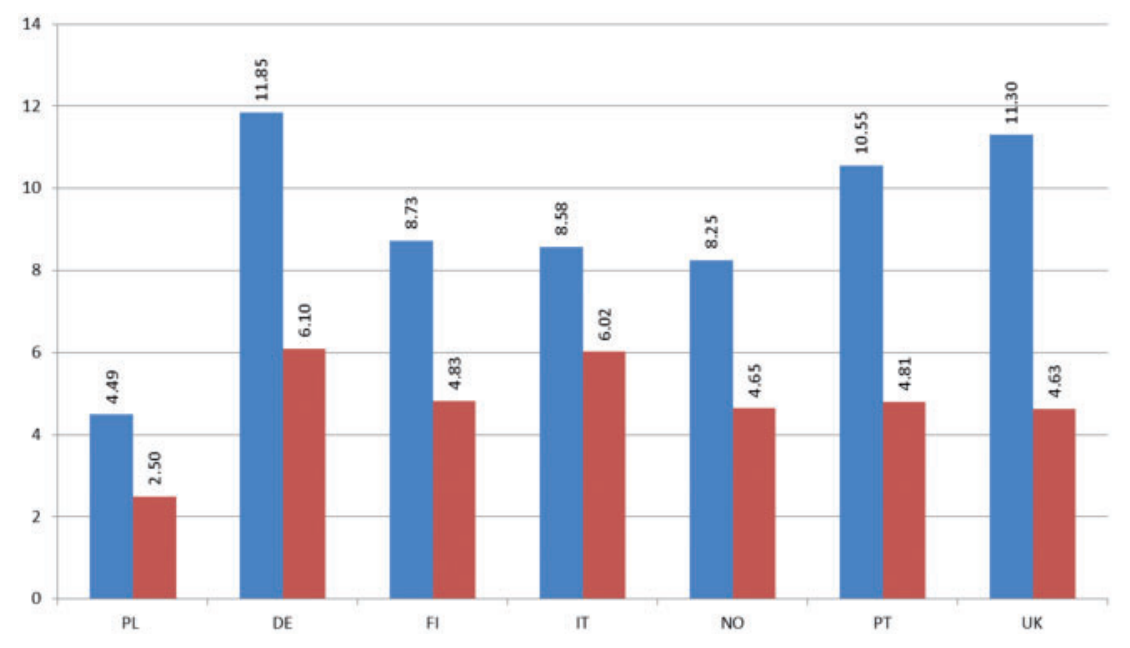

Figure 1. Academic productivity and high academic income: top earners vs. the rest of academics. The average number of 'peer-reviewed article equivalents' published in a three-year reference period (top earners in blue, the rest of academics in red). Only full-time academics employed in universities and involved in both teaching and research are included. Only countries with statistically significant results are included. 


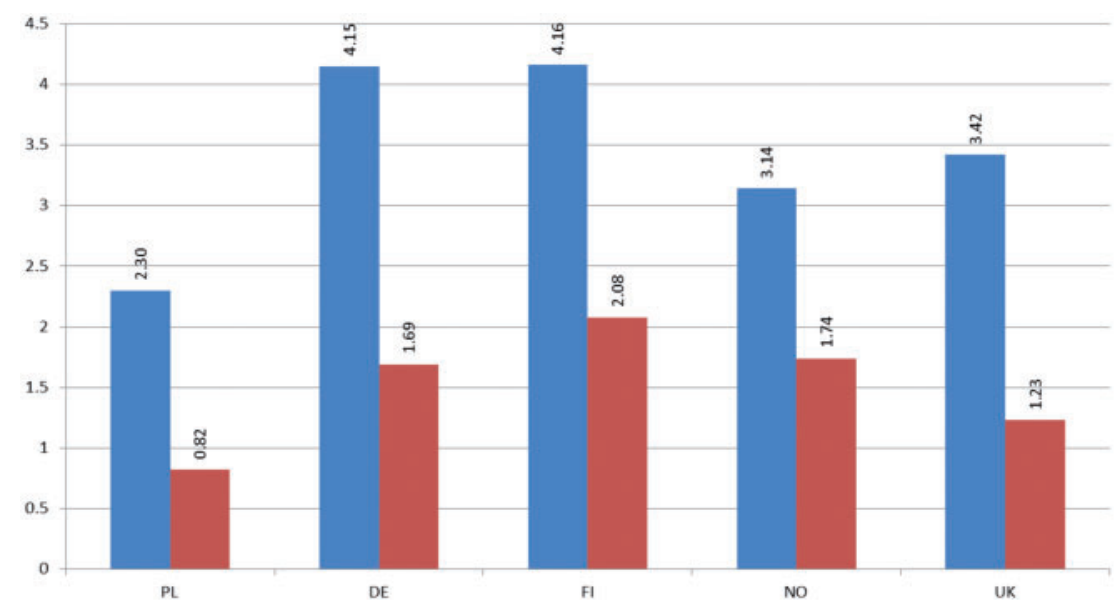

Figure 2. Academic productivity and high academic income: top earners vs. the rest of academics. The average number of 'internationally co-authored article equivalents' published in a three-year reference period (top earners in blue, the rest of academics in red). Only full-time academics employed in universities and involved in both teaching and research are included. Only countries with statistically significant results are included.

Kwiek (2016a))? Yes, they definitely are. For instance, in Germany, on average, 43.1 percent of research top performers are highly paid academics (top earners), and on average, 73.3 percent of the rest of academics are not top earners (Table 5). Our analysis shows that on average, 31.8 percent of national top research performers are among national top earners-from almost 80 percent in the UK to about 40 percent in Finland, Germany, and Portugal and 30 percent in Norway. The only exception is Poland, where top performers are not overrepresented among top earners, constituting merely 22.9 percent of top earners. Poland has a strict national-level fixed salary scheme (see Kwiek (2012; 2016b)). A chi-square test of independence was conducted: there is significant interdependence between the two variables in the six above-mentioned countries. The significance level for all the countries is 0.10 (Table 6).

However, the above results are not multidimensional (the conclusions from the $t$-test analyses are independent of one another), and as such, can be misleading (for instance, the relationship between salary and publication numbers may be influenced by seniority). A study of multidimensional relationships requires the model approach presented below.

\subsection{Logistic regression analysis}

\subsubsection{Procedures and variables in the model}

Like all regression analyses, logistic regression is a form of predictive analysis. It is used to explain the relationship between one dependent binary variable and one or more independent variables. Logistic regression assumes that the dependent variable is a stochastic event and proceeds in terms of likelihoods. The log odds of an event are estimated. The question in this section is how does the probability of being in the upper 20 percent of academic incomes change with changes in various independent variables.

Studies on academic salaries focus on various aspects of academic work: publications and teaching/research abilities (Katz 1973), male and female salaries vis-à-vis research performance (Ferber et al. 1978), the role of citations (Hamermesh et al. 1982), institutional emphasis on research (Konrad and Pfeffer 1990), publications in top-tier journals (Gomez-Mejia and Balkin 1992), journal rankings (Gibson et al. 2014), the maximization of prestige (Melguizo and Strober 2007), academic ranks and strategies to succeed financially (McLaughlin et al. 1979), teaching vs. research (Fairweather 1993, 2005) and others.
Table 5. The share of top earners among research top performers, only countries with statistically significant results.

\begin{tabular}{llll}
\hline & & Rest (nontop earners) & Top earners \\
\hline \multirow{2}{*}{ Finland } & Rest (nontop performers) & 74.5 & 25.5 \\
& Top performers & 59.5 & 40.5 \\
Germany & Rest (nontop performers) & 73.3 & 26.7 \\
& Top performers & 56.9 & 43.1 \\
\multirow{2}{*}{ Norway } & Rest (nontop performers) & 82.7 & 17.3 \\
& Top performers & 66.5 & 33.5 \\
\multirow{2}{*}{ Poland } & Rest (nontop performers) & 85.3 & 14.7 \\
& Top performers & 77.1 & 22.9 \\
\multirow{2}{*}{ Portugal } & Rest (nontop performers) & 79.9 & 20.1 \\
\multirow{4}{*}{ UK } & Top performers & 57.3 & 42.7 \\
& Rest (nontop performers) & 69.4 & 30.6 \\
\multirow{2}{*}{ Total } & Top performers & 22.0 & 78.0 \\
& Rest (nontop performers) & 77.5 & 22.5 \\
& Top performers & 68.2 & 31.8 \\
\hline
\end{tabular}

One persistent dimension of earnings inequality is gender. The gender salary gap has drawn research attention (initially in Anglo-Saxon countries) since the early 1970s (as summarized in Bellas (1993); Fox (1985); Barbezat and Hughes (2005)). While it is uncertain whether gender differences 'reflect differences in human capital or productivity between individuals, discrimination by universities or supply decisions by workers', a common thread that runs through the literature is the 'evidence of the existence of gender differences in salary' (Ward 2001). 'Sex stratification' is reported within the academic profession, and the 'cost of being female' in science is being explored (Bellas 1993: 62). The picture of the USA in the 1980s, as reported by Fox (1985), was as follows: academic tasks (teaching and research) were divided by sex, workplaces were segregated by sex (institutions, fields, and areas) and activities were stratified by sex. Men occupied more superordinate academic ranks and positions, and women occupied more subordinate ranks and positions. Empirical studies have consistently shown a 'substantial unexplained wage gap' in favor of men, and gender is still reported to determine faculty salaries (Toutkoushian et al. 2007: 574). There are also growing cross-disciplinary disparities in academic salaries in more open salary systems (as exemplified by the US system). The disparities across generally less open systems, such as European systems, seem to be more restrained (Stephan 2012). 
Table 6. Chi-square independence test statistics.

\begin{tabular}{|c|c|c|c|c|c|c|c|c|c|c|}
\hline Statistics & AT & FI & $\mathrm{DE}$ & IT & NL & NO & PL & PT & $\mathrm{CH}$ & UK \\
\hline Chi-square & 0.455 & 3.637 & 3.493 & 1.364 & 0.229 & 7.636 & 7.666 & 3.41 & 0.54 & 10.698 \\
\hline $\mathrm{df}$ & 1 & 1 & 1 & 1 & 1 & 1 & 1 & 1 & 1 & 1 \\
\hline P-value & 0.5 & 0.057 & 0.062 & 0.243 & 0.633 & 0.006 & 0.006 & 0.065 & 0.462 & 0.001 \\
\hline
\end{tabular}

Research consistently shows scholarly productivity to be a strong correlate of faculty pay. Teaching has been typically shown to be unrelated to or to be a negative factor in faculty compensation (see Katz (1973); McLaughlin et al. (1979); Hamermesh et al. (1982); Konrad and Pfeffer (1990); Fairweather (1993); Gomez-Mejia and Balkin (1992); Fairweather (2005); Melguizo and Strober (2007); and Gibson et al. (2014)). The quality of research (as measured by citations) is rewarded by the academic market (Hamermesh et al. 1982: 481): 'an additional reference adds more to salary than does the publication of an additional book or article.' The regression results show that spending more hours in the classroom is related to a lower basic salary and that publishing productivity is a significant positive factor in pay at all types of institutions (Fairweather 2005: 416-17).

Based on the research literature and given the limitations of the dataset at our disposal, specifically the lack of a link between individual observations and bibliometric data, we developed an analytical model to study academic salaries. Specifically, we employed selected variables found in McLaughlin et al. (1979), Gomez-Mejia and Balkin (1992), Fairweather (1993), Melguizo and Strober (2007), and Shen and Xiong (2015). In this multivariate analysis, we dichotomized all category variables through a recoding procedure. We started with forty-two personal and institutional characteristics, which were grouped into eight clusters: personal/demographics, socialization, internationalization, academic behaviors, academic attitudes and role orientation, overall research engagement, institutional policies, and institutional support. We then conducted Pearson Rho's correlation tests to find significantly correlated predictors of the dependent variable. High intercollerations among the predictors (multicollinearity) were tested using an inverse correlation matrix because a correlation matrix refers only to pairwise correlations of independent variables. On the main diagonal of an inverse correlation matrix, there are values without unequivocal interpretation; however, they show how strongly a given variable is correlated with all other variables. The interpretation is performed in such a way that all variables with diagonal values higher than 4 are removed from the analysis. In our case, there was only one such value ('peer-reviewed article equivalent', diagonal value: 4.222); however, because it did not significantly exceed the conventional boundary value of 4 , it was left in the model. Diagonal values of the inverse correlation matrix are given in Table 12 in the Supplementary Material. Also, principal component analysis (PCA) was performed to determine whether any variables, due to their high level of correlation, could be grouped into homogenous groups. No significant interdependence between any of the variables was found.

We also used two robustness checks. The first was an examination of pairwise correlations, particularly between the status of professors, age and the productivity measures. It may be that most of the effect of research productivity is captured by the professor variable. The status of professors was moderately and positively correlated with age $(r=0.33)$, which is understandable. We used five productivity measures: scholarly books authored or coauthored, peer-reviewed article equivalents, internationally coauthored article equivalents, foreign language article equivalents, and papers presented at scholarly conference. The correlation between the status of professor with our productivity measures was indeed positive but weak (in the $r=0.11-0.18$ range). The second robustness check was to run the model without the professor variable and see how the results changed. We ran a pooled model across all countries with the professor variable and without it. In both models, all productivityrelated variables were statistically insignificant. However, in the former model, the professor variable somehow inherently included several variables traditionally associated with being a professor (such as being a peer reviewer, being an editor of journals or book series or belonging to national or international committees, boards and bodies, which were all statistically insignificant). When the professor variable was removed from the model, all these variables emerged as significant. Surprisingly, there was a difference between productivity-related variables (which were insignificant) and prestige-related variables (which were significant only in the model without the professor variable).

The model was estimated using a stepwise backward elimination based on the Wald criteria, so only significant variables were included in the models for each country. We estimated a regression model for eight of the ten countries to highlight cross-national differences among top earners (for Portugal and the UK, the character of data did not allow the use of the maximum likelihood estimator). The models were fitted correctly: neither over-fitting nor under-fitting occurred. Only meaningful variables were included, and all meaningful variables were included. Each observation was independent. The predictive power of the fourth model, as measured by Nagelkerke's $R^{2}$, was generally high, and it was the highest for Finland (0.82), followed by Switzerland, Germany, and the Netherlands (in the 0.60-061 range); it was 0.45 for Italy and in the range of $0.29-0.30$ for Austria, Norway, and Poland. The total average variance demonstrated for the eight countries was 49.66 percent. In Table 7 , we present the results of the fourth model, which is the final model.

\subsubsection{Statistically significant variables}

Institutional variables did not enter into the equation in any of the countries studied. The importance of individual-level variables differs from country to country. In the first block of individual predictors ('personal/ demographics'), age entered into the equation in the majority of countries. Age is a strong predictor of being an academic top earner in Germany, Finland, Italy, Poland, and the Netherlands: on average, a one-unit increase (i.e. 1 year) increases the odds of being a top earner by as much as 29 percent in Finland and 20 percent in the Netherlands, as well as by 17 percent in Italy, 12 percent in Germany and 4 percent in Poland (ceteris paribus) for the specific older academic cohort explored here. This finding is consistent with the conclusions of Melguizo and Strober (2007) and McLaughlin et al. (1979), who emphasized positive correlations between age and salaries. In Norway, where age did not enter into the equation, the predictor 'years since first full-time employment' (or academic age) did: on average, a 1-year increase in academic age increased the odds of becoming a top earner by 5 percent and, unexpectedly, decreases the odds of becoming a top earner by 18 percent in Finland. The only exceptions in our pool of countries were 
Table 7. Odds ratio estimates by logistic regression for being in the top $20 \%$ in total gross academic income, all nine countries.

\begin{tabular}{|c|c|c|c|c|c|c|c|c|}
\hline Nagelkerke's $R^{2}$ & $\begin{array}{c}\text { AT } \\
0.302\end{array}$ & $\begin{array}{c}\mathrm{CH} \\
0.608\end{array}$ & $\begin{array}{c}\mathrm{DE} \\
0.61\end{array}$ & $\begin{array}{c}\text { FI } \\
0.822\end{array}$ & $\begin{array}{c}\text { IT } \\
0.449\end{array}$ & $\begin{array}{c}\text { NO } \\
0.298\end{array}$ & $\begin{array}{c}\text { PL } \\
0.286\end{array}$ & $\begin{array}{c}\text { NL } \\
0.598\end{array}$ \\
\hline \multicolumn{9}{|l|}{ Personal/demographics } \\
\hline Age & & & $1.124 * *$ & $1.287^{*}$ & $1.174 * * *$ & & $1.043 *$ & $1.201^{*}$ \\
\hline Female & & & & & & & $0.379 * *$ & \\
\hline Professor & $12.419 * * a$ & $15.171^{* * a}$ & $77.322 * * * a$ & $2588.019 * * * a$ & $8.334 * * *$ & $3.267 * *$ & $3.219^{* * *}$ & $78.745^{* * a}$ \\
\hline Cluster of hard sciences & & & $5.14 *$ & $44.523 * * a$ & & & $0.43 * *$ & \\
\hline Years since first full-time appointment & & & & $0.814 *$ & & $1.045^{*}$ & & \\
\hline \multicolumn{9}{|l|}{ Academic behaviors } \\
\hline $\begin{array}{l}\text { Annualized (proxy: } 60 \% \text { in session, } 40 \% \\
\text { not in session) mean weekly teaching hours }\end{array}$ & & & $0.925^{*}$ & & & $0.953^{*}$ & & \\
\hline \multicolumn{9}{|l|}{ Annualized mean weekly research hours } \\
\hline Annualized mean weekly service hours & & $1.17^{* *}$ & & & & & $1.104 * * *$ & \\
\hline Annualized mean weekly administrative hours & & & & $1.466 * *$ & & $1.061^{*}$ & $1.07^{*}$ & \\
\hline Annualized mean weekly other hours & & $1.241^{*}$ & & & & & & \\
\hline \multicolumn{9}{|l|}{ Academic attitudes and role orientation } \\
\hline Research-oriented ('Primarily in research') & & & & $68.817 * * \mathrm{a}$ & $2.573^{*}$ & & & \\
\hline Teaching-oriented ('Primarily in teaching') & & & $34.68 * a$ & & & & & \\
\hline Basic/ theoretical research & & $7.39^{*}$ & & & & & & \\
\hline Applied/ practically-oriented & & & & & & & & \\
\hline Commercially oriented/intended for technology transfer & & & & $0.004 * * a$ & $2.312 *$ & $5.656 *$ & & \\
\hline \multicolumn{9}{|l|}{ Internationalization and collaboration } \\
\hline \multicolumn{9}{|l|}{ Collaborating internationally in research } \\
\hline Research international in scope or orientation & & & & $33.982 * \mathrm{a}$ & & & & \\
\hline \multicolumn{9}{|l|}{ Overall research engagement } \\
\hline A peer reviewer & & & & $7.447^{*}$ & & & & \\
\hline \multicolumn{9}{|l|}{ Editor of journals/book series } \\
\hline \multicolumn{9}{|l|}{ National/international committees, boards, bodies } \\
\hline Being a research top-performer (the upper $20 \%$ ) & & & & & & $2.521^{*}$ & $3.559 * *$ & \\
\hline Scholarly books authored or coauthored & $0.598^{*}$ & & & $3.071^{*}$ & & & & \\
\hline Peer-reviewed article equivalent published & & & $0.94 *$ & & & & & \\
\hline Internationally coauthored article equivalent published & & & $1.187^{*}$ & $0.611^{* *}$ & & & & \\
\hline Foreign language article equivalent published & & & & $1.358 * *$ & $1.034^{*}$ & & & \\
\hline Papers presented at a scholarly conference & & & & $0.885^{* *}$ & & & & \\
\hline Patent or invention & $2.283^{*}$ & & & $9.99 *$ & & & & \\
\hline Constant & $0.199 * * *$ & $0.005 * *$ & $0 * * *$ & $0 * *$ & $0 * * *$ & $0.038 * * *$ & $0.015^{* * *}$ & $0 * *$ \\
\hline
\end{tabular}

Results that are not statistically significant are not shown in the Table.

$* \mathrm{P}<0.05, * \mathrm{P}<0.01, * * \mathrm{P}<0.001$

${ }^{\text {a }}$ These odds ratios need to be treated with caution.

Austria and Switzerland, where neither age nor academic age was statistically significant.

Interestingly, being a female academic entered into the equation only in Poland. It is a very strong predictor of not being a top earner there. In Poland, the odds ratio value indicates that female academics are, on average, highly unlikely (about one-third as likely as male academics) to be top earners $(\operatorname{Exp}(B)=0.379)$. It is important to remember that the cohort studied is aged 40 years and more and has a minimum of 10 years of academic experience. In all other countries, being a female academic is not a statistically significant variable. This finding does not confirm the conclusions of earlier academic salary studies (Fox 1985; Bellas 1993; Ward 2001; and Balkin and Gomez-Mejia 2002), specifically the research findings of a long list of Anglo-Saxon pay equity studies focused on gender salary gaps (Barbezat 2002; Barbezat and Hughes 2005). However, it is consistent with more recent studies (e.g. Melguizo and Strober 2007), which show limited correlation between gender and earnings and the potential impact of institutional and/or national policy corrective actions. This research explores highly paid European academics, rather than all academics, and the odds of entering this peculiar group. Being a professor (or academic seniority) emerged as an important variable in the model, with statistical significance in all countries; however, the odds ratios for five of these countries should be treated with caution (limited numbers of observations). In the other countries, being of a senior rank increases the odds of being a top earner by about eight-fold in Italy and about three-fold in Norway and Poland. Again, consistent with previous studies, European academics are certainly more likely to be promoted to higher ranks if and when they are older (Barbezat and Donihue 1998) as their publication lists become longer, which is consistent with human capital (Becker and Toutkoushian 2003; Toutkoushian and Paulsen 2016) and prestige models of academic salaries (Melguizo and Strober 2007). Professorship and academic seniority certainly affect academic income levels, as we would expect from human capital theory, and the relationship is reciprocal (Katz 1973; Fairweather 2005): correlates of high incomes do not necessarily indicate causal relationships. The cluster of hard sciences entered into the equation in two countries, with ambiguous results. The decrease in the odds of becoming a top earner in this cluster in Poland $(\operatorname{Exp}(B)=0.43)$ is consistent with recent analyses of the Polish academic profession in which university salaries in the natural sciences and life sciences are lower than the institutional average (Kwiek 2015b,c).

In the block of 'academic behaviors', annualized mean research hours per week did not emerge as a determinative predictor of becoming a top earner in any country. In a similar vein, only in Poland and Germany did annualized mean weekly teaching hours emerge as a determinative predictor: on average, a unit increase of 1 hour decreased the odds of becoming a top earner by about 5 percent in the former and 7 percent in the latter (ceteris paribus), which 
is consistent with the vast teaching/research trade-off literature. This is perhaps the most perplexing finding of this research: contrary to most of the extant literature (specifically Katz (1973); Dillon and Marsh 1981; Hamermesh et al. (1982); Fairweather (1993)) in the majority of the European countries studied, neither teaching nor research hours are statistically significant predictors of higher academic incomes.

In the case of teaching/research time investments, the results of the bivariate analysis and regression analysis point in the same direction. Traditionally, long research hours were reported to be strongly correlated with higher academic incomes, and long teaching hours were reported to be correlated with lower academic incomes. Our research does not support these claims in the specific case of European academics. However, previous research was predominantly focused on Anglo-Saxon academics and on all incomes rather than higher incomes. There is an important qualification: the measure used refers to the current time only; past time investments in research cannot be grasped with the instrument used. Annualized mean weekly service hours, in turn, entered into the equation in two countries (Switzerland, where a unit-increase of 1 hour per week increases the odds of becoming a top earner by about 17 percent on average, and Poland, where such an increase in mean weekly service hours increased the odds of becoming a top earner by about 10 percent on average). Annualized mean weekly administrative hours entered the equation in three countries (increasing the odds by about 47 percent in Finland, 6 percent in Norway, and 7 percent in Poland on average and ceteris paribus). Finally, 'other' hours emerged as a strong predictor in Switzerland (increasing the odds of becoming a top earner by about 24 percent on average). However, 'total working hours' did not enter into the equation in any of the countries studied, which may indicate the importance of a specific working time distribution rather than long working hours (in contrast to the case of European research top performers analyzed in Kwiek (2015a), for whom all types of hours, except for teaching hours, were longer; from a cross-generational perspective, see Kwiek (2015c) and Kwiek and Antonowicz (2014)). In the case of teaching/ research time investments-as well as administration and service time investments-the results of the bivariate analysis and the regression analysis again point in the same direction, consistent with McLaughlin et al. (1979: 32), who link individual strategies to succeed financially with academic rank ladders and suggest avoiding too much teaching in the early stages of one's career and focusing on administration in the later stages of one's academic career: 'an administrative assignment for an established professor will increase the likelihood for salary increases.'

Being in the 'academic attitudes and role orientation' block that was interested 'primarily in research' emerged as a strong predictor in only one country, Italy (increasing the odds of becoming a top earner by more than two-and-a-half-fold on average). This was surprising in the context of the existing literature, in which the research role orientation matters considerably in terms of higher salaries (e.g. Stephan (1996); Konrad and Pfeffer (1990)). Characterizing one's primary research as 'commercially-oriented or intended for technology transfer' substantially increases the odds of becoming a top earner in two countries: by almost two-and-a-half-fold in Italy and by about 5.7-fold in Norway. An interest in 'basic/theoretical research' increases the odds of becoming a top earner by 7.4-fold in Switzerland. Overall, different academic attitudes and role orientations (especially a preference for teaching or research) did not emerge as statistically important (the same results were achieved in the bivariate correlational analysis, which is not reported here due to space limits). In the 'internationalization and collaboration' block, no predictors entered the equation.

Finally, inconsistent with the conclusions from most of the literature referred to in Section 2 (especially Gomez-Mejia and Balkin (1992); Fairweather (1993); and McLaughlin et al. (1979)), in the 'overall research engagement' block, selected academic researchrelated and prestige-related activities, as well as high research productivity, did not emerge as highly determinative. High individual academic productivity_being a research top performer, defined as being in the upper 20 percent of the productivity scale and measured separately for major clusters of academic fields-entered into the equation in only two countries, increasing the odds in Poland (more than three-and-a-half-fold on average) and in Norway (more than two-and-a-half-fold on average, in both cases ceteris paribus). In other countries, high academic productivity did not have a statistically significant effect on becoming a top earner. Being a peer reviewer emerged as a significant variable in the model in only one country, Finland (with $\operatorname{Exp}(\mathrm{B})=7.447$ ). Sitting on national and international committees, boards and bodies did not emerge as significant in any of the countries. The same was true for being an editor of a journal (or a book series). Having a patent or invention within the reference period of 3years emerged as significant in two countries (Austria, $\operatorname{Exp}(B)=2.283$ and Finland, $\operatorname{Exp}(B)=9.99$ ).

Also, the variables related to publications (such as scholarly books authored or coauthored, peer-reviewed article equivalents published, internationally coauthored article equivalents published, and foreign language article equivalents published) did not emerge as unambiguous determinative variables in most of the countries studied. For instance, books published increased the odds of becoming a top earner substantially (three-fold) in Finland, but decreased them in Austria. Also, peer-reviewed article equivalents published entered into the equation in only one country: they actually decreased the odds of becoming a top earner by 6 percent in Germany. Finally, another dimension of research activities-the number of papers presented at a scholarly conference-actually decreased the odds of being a top earner in Finland (by 11 percent) and was statistically insignificant in all other countries.

Finally, a third robustness check was performed by running the model with a higher cut-off point. We examined the upper 15 percent (instead of the upper 20 percent), as contrasted with the rest of academics, and compared the differences. The predictive power of the fourth model, as measured by Nagelkerke's $R^{2}$, was roughly the same, being slightly higher for five countries (Austria, Switzerland, Italy, Norway, and Poland) and slightly lower for the remaining three (Germany, Finland, and the Netherlands). The total average variance demonstrated for the eight countries was similar (50.11 percent). As in the first model, being a female academic emerged as a statistically significant variable (in Italy, Norway, and Poland), and the odds ratio values indicate that female academics are, on average, highly unlikely (about one-third to one-fourth as likely as male academics) to become top earners $(\operatorname{Exp}(B)=0.274$ 0.379). The hard sciences cluster emerged as statistically significant, substantially decreasing the odds of being among the top earners in four countries (Austria, Italy, Norway, and Poland, with $\operatorname{Exp}(B)=0.248-0.360)$. Annualized mean weekly research hours were shown to decrease the odds of becoming a top earner in Austria, Italy, and Poland (with $\operatorname{Exp}(\mathrm{B})=0.926-0.969)$. Annualized mean weekly service hours, in turn, increased the odds of becoming a top earner in all countries, except Austria and Finland (with $\operatorname{Exp}(B)=1.066-1.201$ ), as did annualized mean weekly 'other' hours in Germany and Italy (with $\operatorname{Exp}(\mathrm{B})=1.057$ and $\operatorname{Exp}(\mathrm{B})=1.090$, 
respectively). Also, similar to the first model, a research orientation increases the odds of becoming a top earner (in Austria and Italy), papers presented at scholarly conferences decrease these odds (in Austria and Finland) and having a patent or invention increases these odds (in Austria and Finland).

Thus, overall research engagement-as studied through many variables in the model—proves to be largely statistically insignificant as a predictor of belonging to the class highly paid academics. Relatively weak correlations between various research-related activities (such as being a top research performer or the number of peerreviewed article equivalents, conference papers, etc.), various prestige-related academic activities (such as being a journal editor or sitting on national and international scientific committees) and academic incomes are largely inconsistent with earlier conclusions based on studies of the American academic profession. These results do not confirm the results of the bivariate analysis and indicate that the use of parallel methods is more useful than a focus on single methods. The European/American academic profession split revealed in this research may be related both to the more general ideas organizing research-based academic careers and academic salaries and, more practically, to greater leeway due to the better funding of American universities. There is also an important distinction to be made between the determinants of academic incomes in general and the predictors of high academic incomes studied in this article. A tentative conclusion could be that the focus on older academic cohorts and high academic incomes amplifies the differences between the American academic profession (as traditionally explored in academic salary studies) and the European academic profession.

\section{Discussion and conclusions}

This article is an empirically based comparative study of highly paid academics in Europe, and it uses a large dataset of behaviors, attitudes, and perceptions of the European academic profession (CAP/ EUROAC, $N=17,211$ ). We have examined ten European systems, and our focus was restricted to full-time academics involved in both teaching and research who were employed in a specific institutional type: the university. A class of academic 'top earners' (from the age cohort of 40 years old and more having a minimum of 10 years of academic experience) was explored to explore various aspects of their working time distribution and research productivity. Finally, the predictors of becoming an academic top earner were examined from a cross-national European perspective.

To a large extent, the findings obtained via a multidimensional model approach support the findings of inferential statistics: interestingly, in the context of previous (mostly) single-nation studies, research time for the academic cohort studied is not positively correlated with high incomes, teaching time is not negatively correlated with high incomes, and there is almost no correlation between the research role orientation or gender and high incomes. Interestingly, the strong correlations between high productivity and high incomes seen in the bivariate analysis are not confirmed in the regression analysis. The research focus of this article was on high incomes in an older cohort of academics and the odds of receiving them, rather than-as in traditional academic salary studies-all academics and all academic incomes in general. Consequently, this research explores cross-national academic salaries via new questions (top earners, as contrasted with the rest of academics, and the predictors of being a top earner) applied to new (i.e. older) academic cohorts in new (i.e. European) national settings.
This research project has two types of implications: implications for current theoretical models and assumptions in salary studies, as well as policy implications for institutions and national systems. Starting with the former, our findings tend to suggest that the traditionally explored link between higher time investments in research and higher academic incomes-consistently demonstrated for AngloSaxon countries over the last four decades (as in Katz (1973); Konrad and Pfeffer (1990); Fairweather (1993); Gomez-Mejia and Balkin (1992); Fairweather (2005); Melguizo and Strober (2007); and Gibson et al. (2014)) —-may not hold across Europe today as strongly as in Anglo-Saxon systems. As Fairweather (1993: 629) expressed, the traditional view is that 'faculty who spend more time on research and who publish the most are paid more than their teaching-oriented colleagues', and the American academe is moving toward 'a single faculty reward structure, one dependent on publishing, spending time on research, and minimizing involvement in instruction'. National academic labor markets in Europe, as is clear from this research, are homogenous and research-based, rather than segmented (Fairweather 2005): teaching-oriented institutions do not seem to be paying their top teachers more, while all institutions tend to pay their top performers more. For European universities, academic pay does not seem to be influenced-as in labor economics (Toutkoushian and Paulsen 2016) — by the demand for higher education services or the supply of qualified individuals. According to our results, highly productive academics are disproportionately over-represented among highly paid academics across Europe: on average, 31.8 percent of top national research performers are among national top earners, with this percentage ranging from almost 80 percent in the UK to about 40 percent in Finland, Germany, and Portugal. The correlations between high incomes and high performance are strong.

Given that European higher education research stands in the shadow of its American counterpart, especially in terms of its basic theoretical frameworks, this article suggests a more sustained focus on cross-national (not to say cross-continental) differences in higher education and on the role of various national traditions in the academic enterprise in the future. We suggest rethinking the potential over-reliance on American research findings in discussing academic salaries in non-American contexts. Some theoretical frameworks and analytical concepts stand firm and are useful on both sides of the Atlantic, while others may not be as useful.

"Large-scale" differences in the organization and funding of Anglo-Saxon (and especially American) higher education systems and European ones may suggest rethinking not only the analytical frameworks used to explore academic salaries but also those used to explore various aspects of higher education that are specifically linked to national traditions. They include, for instance, costsharing, fees and loans, public and private goods in higher education, typologies of university governance models and others.

The results of our analysis are not consistent with traditional (mostly US-focused) academic salary research, which tends to emphasize strong positive correlations between salaries and long research hours, combined with a strong research focus; however, our results are consistent with those of traditional research in terms of showing correlations between high salaries and high productivity. The interesting point is that individual productivity also includes coauthored productivity. Therefore, high productivity must not necessarily be correlated with longer research hours. One indication that the high earners in our sample may be involved in the extensive supervision of collective research grants and/or leading research groups, heading departments or faculties, etc. is the finding that they tend to spend more time on administration, service, and other 
academic duties. For instance, top earners in Germany and Switzerland work, on average, 8 more hours per week than the rest of academics in the same older cohorts. This indicates, on average, 5 more administrative hours in Germany and 10 more service hours in Switzerland, with no statistically significant difference in traditionally explored teaching and research hours.

Thus, the US salary system (with highly differentiated salary levels across institutions) and European salary systems (with low national pay differentials) certainly have one point in common: the higher average research productivity of highly paid academics. However, while in the USA, longer research hours, a stronger research focus and higher research productivity seem to pay off directly, in Europe, only higher research productivity seems to matter directly in determining individual salary levels. On top of that, high productivity determines high salaries only in combination with more time being spent on nonresearch academic activities outside the traditional teaching and research dyad.

At a policy level, a more direct research-income link in the USA as compared with European countries may result in the everstronger siphoning of research-focused academics with higher 'tastes for science' (Roach and Sauermann 2010) (those who want to have better salaries and do not want to be involved in university administrative duties) from European to American universities. Academic salaries and the distribution of research/nonresearch time are at the core of the traditional university enterprise. The questions of what to do (proportions of teaching, research and administration time and whether to conduct basic or applied research) and where to be (at which institution, in academia or industry and possibly in which national system) are looming not only for individual academics but also at the institutional and national levels, guiding institutional (Pinheiro et al. 2012; Stensaker et al. 2012) and national (Enders et al. 2011; Musselin and Teixeira 2014) higher education reform agendas. Our research strongly supports findings about the 'asymmetric international mobility' of talented scientists between Europe and the USA, as recently studied by Janger and Nowotny (2016). While top researchers certainly attract other top researchers and the attractiveness of an academic job increases with its salary, job choice is 'not driven by the remuneration package alone' (Janger and Nowotny 2016: 1679). There seems to be a " global" view on which [academic] jobs are attractive, explaining the international mobility of scientists towards countries where jobs with these characteristics are more common' (Janger and Nowotny 2016: 1681).

This research shows that while in Anglo-Saxon countries, the university research mission traditionally pays off at an individual level, in Europe, it pays off in combination with administrative and related duties. Seeking future financial rewards through research in Europe seems difficult, except for highly productive academics, but seeking satisfaction through solving research puzzles is also becoming more difficult than ever before because of the growing emphasis on the relevance and applicability of fundable research (Teichler et al. 2013). Thus, because both the traditional 'investment motivation' and the 'consumption motivation' for research (Levin and Stephan 1991) are scarce in European academia today, nationallevel and institutional-level policies may need to be rethought so that the best and brightest will still seek and maintain academic employment in European higher education in the context of an 'exodus of European researchers' (Docquier and Rapoport 2012: 715).

Certainly, the conditions of the academic profession vary from country to country across the continent (Janger et al. 2013), with Switzerland being the most attractive and Poland being the least attractive in the sample when viewed through the proxies of average academic job satisfaction, average salary level, and willingness to leave the academic profession. There are many employment options to choose from today, and studies of the academic profession show an ever-shorter list of 'non-pecuniary advantages' and an everlonger list of 'pecuniary disadvantages' (Ward and Sloane 2000) for academic positions in European universities. The intersection of high research performance and high academic salaries is one of the most consequential testing grounds for the attractiveness of the academic profession in the future.

\section{Supplementary data}

Supplementary data is available at Science and Public Policy Journal online

\section{Acknowledgements}

The author gratefully acknowledges the support of the National Research Council (NCN, Grant DEC-2011/02/A/HS6/00183) and wishes to thank Ulrich Teichler, the coordinator of the European Science Foundation EUROAC research project, 'Academic Profession in Europe: Responses to Societal Challenges', and Jung Cheol Shin, the organizer of 'The Fourth International Conference on Academic Profession in Knowledge Society' (April 20-22, 2016, Seoul National University, Korea), as well as participants in this conference for their valuable comments. Dr Wojciech Roszka's assistance was substantial. Finally, the author wishes to express his gratitude to anonymous reviewers for their highly constructive suggestions.

\section{References}

Agarwal, R. and Ohyama, A. (2012) 'Industry or Academia Basic or Applied? Career Choices and Earnings Trajectories of Scientists', Management Science, Advance access, 1-21.

Altbach, P. G. (ed.) (2002) The Decline of the Guru: The Academic Profession in Developing and Middle-Income Countries. Chestnut Hill: CIHE Boston College.

— et al. (2012) Paying the Professoriate. A Global Comparison of Compensation and Contracts. New York: Routledge.

Balkin, D. B., and Gomez-Mejia, L. R. (2002) 'Explaining the Gender Effects on Faculty Pay Increases', Group of Organization Management, 27/3: 352-73.

Barbezat, D. A. (2002) 'History of Pay Equity Studies'. New Directions for Institutional Research, 115: 9-40.

Barbezat, D. A. and Donihue, M. R. (1998) 'Do Faculty Salaries Rise with Job Seniority?', Economics Letters, 58/2: 239-44.

- and Hughes, J. W. (2005) 'Salary Structure Effects and the Gender Pay Gap in Academia', Research in Higher Education, 46/6: 621-40.

Becker, W. E., and Toutkoushian, R. K. (2003) 'Measuring Gender Bias in the Salaries of Tenured Faculty Members', New Directions for Institutional Research, 117/Spring: 5-18.

Bellas, M. L. (1993) 'Faculty Salaries: Still a Cost of Being a Female?', Social Science Quarterly, 74/1: 62-75.

Bentley, P. J. and Kyvik, S. (2013) 'Individual Differences in Faculty Research Time Allocations Across 13 Countries.' Research in Higher Education, 54/ 3: 329-348.

Blackmore, P. (2016) Prestige in Academic Life. Excellence and Exclusion. London: Routledge.

Blau, P. M. (1994) The Organization of Academic Work. New Brunswick: Transaction Publishers.

Brewer, D. J., Gates, S. M., and Goldman, C. A. (2002) In Pursuit of Prestige: Strategy and Competition in U.S. Higher Education. New Jersey: Transaction Publishers.

Dillon, K. E., and Marsh, H. W. (1981) 'Faculty Earnings Compared with Those of Nonacademic Professionals', The Journal of Higher Education, 52/6: 615-23. 
Docquier, F., and Rapoport, H. (2012) 'Globalization, Brain Drain and Development', Journal of Economic Literature, 50/3: 681-730.

Enders, J., and de Weert, E. (2004) The International Attractiveness of the Academic Workplace in Europe. Frankfurt: GEW.

— Education in Europe. Rotterdam: Sense.

Fairweather, J. S. (1993) 'Faculty Reward Structures: Toward Institutional and Professional Homogenization', Research in Higher Education, 34/5: 603-23.

— (1995) 'Myths and Realities of Academic Labor Markets', Economics of Education Review, 14/2: 179-92.

- (2005) 'Beyond the Rhetoric: Trends in the Relative Value of Teaching and Research in Faculty Salaries', The Journal of Higher Education, 76/4: 401-22.

Ferber, M. A. (1974) 'Professors, Performance, and Rewards', Industrial Relations, 13/February: 69-77.

— L Loeb, J. W., and Lowry, H. M. (1978) 'Sex Differentials in the Earnings of PhDs', Industrial and Labor Relations Review, 13/Summer: 385-401.

Fox, M. F. (1985) 'Location, Sex-Typing, and Salary among Academics', Work and Occupations, 12/2: 186-205.

Gibson, J., Anderson, D. L., and Tressler, J. (2014) 'Which Journal Rankings Best Explain Academic Salaries? Evidence from The University of California', Economic Inquiry, 52/4: 1322-40.

Gomez-Mejia, L. R., and Balkin, D. B. (1992) 'Determinants of Faculty Pay: An Agency Theory Perspective', Academy of Management Journal, 35/5: 921-55.

Hamermesh, D. S., Johnson, G. E., and Weisbrod, B. A. (1982) 'Scholarship, Citations and Salaries: Economic Rewards in Economics', Southern Economic Journal, 49/2: 472-81.

Janger, J., and Nowotny, K. (2016) 'Job Choice in Academia', Research Policy, 45/8: 1672-83.

— Strauss, A., and Campbell, D. (2013) 'Academic Careers: A Crosscountry Perspective', WWWforEurope Work. Pap. Ser., 2013, 37. <http:// www.foreurope.eu/fileadmin/documents/pdf/Workingpapers/ WWWforEurope_WPS_no037_MS64.pdf > .

Katz, D. A. (1973) 'Faculty Salaries, Promotions, and Productivity at a Large University', The American Economic Review, 63/3: 469-77.

Konrad, A. M., and Pfeffer, J. (1990) 'Do You Get What You Deserve? Factors Affecting the Relationship between Productivity and Pay', Administrative Science Quarterly, 35/2: 258-85.

Kwiek, M. (2012) 'Changing Higher Education Policies: From the Deinstitutionalization to the Reinstitutionalization of the Research Mission in Polish Universities', Science and Public Policy, 35/5: 641-54.

- (2015a) 'The Internationalization of Research in Europe. A Quantitative Study of 11 National Systems from a Micro-Level Perspective', Journal of Studies in International Education, 19/2: 341-59.

- (2015b) 'The Unfading Power of Collegiality? University Governance in Poland in a European Comparative and Quantitative Perspective', International Journal of Educational Development, 43: 77-89.

- $(2015 \mathrm{c})$ 'Academic Generations and Academic Work: Patterns of Attitudes, Behaviors and Research Productivity of Polish Academics after 1989', Studies in Higher Education, 40/8: 1354-76.

- (2016a) 'The European Research Elite: A Cross-National Study of Highly Productive Academics across 11 European Systems', Higher Education, 71/3: 379-97.

- (2016b) 'De-privatization in Higher Education: A Conceptual Approach', Higher Education, doi: 10.1007/s10734-016-0047-3 (published online 18 August 2016).

— and Antonowicz, D. (2014) 'The Changing Paths in Academic Careers in European Universities: Minor Steps and Major Milestones'. In: T., Fumasoli, G., Goastellec, B. M., Kehm (eds.) Academic Work and Careers in Europe Trends, Challenges, Perspectives, pp. 41-68. Dordrecht: Springer.

Kyvik, S. (1990) 'Age and Scientific Productivity. Differences between Fields of Learning', Higher Education, 19: 37-55.

Levin, S., and Stephan, P. E. (1991) 'Research Productivity over the Life Cycle: Evidence for Academic Scientists', The American Economic Review, 81/1: $114-32$.
McLaughlin, G. W., Montgomery, J. R., and Mahan, B. T. (1979) 'Pay, Rank, and Growing Old with More of Each', Research in Higher Education, 11/1: 23-35.

Melguizo, T., and Strober, M. H. (2007) 'Faculty Salaries and the Maximization of Prestige', Research in Higher Education, 48/6: 633-68.

Musselin, Ch. and Teixeira, P. N. (eds.) (2014) Reforming Higher Education. Public Policy Design and Implementation. Dordrecht: Springer.

Nanbu, H., and Amano, T. (2015) 'Labor Conditions'. In: A., Arimoto, W. K., Cummings, F., Huang and J. C., Shin (eds.) The Changing Academic Profession in Japan, pp. 119-33. Dordrecht: Springer.

Over, R. (1982) 'Does Research Productivity Decline with Age?', Higher Education, 11: 511-20.

Pinheiro, R., Benneworth, P. and Jones, G. A. (eds.) (2012) Universities and Regional Development: A Critical Assessment of Tensions and Contradictions. London: Routledge.

RIHE (2008) The Changing Academic Profession over 1992-2007: International, Comparative, and Quantitative Perspective. Hiroshima: RIHE.

Roach, M., and Sauermann, H. (2010) 'A Taste for Science? PhD Scientists' Academic Orientation and Self-Selection into Research Careers in Industry', Research Policy, 39: 422-34.

Rumbley, L. E., Pacheco, I. F., and Altbach, P. G. (2008) International Comparison of Academic Salaries. An Exploratory Study. Boston: CIHE.

Shen, H. and Xiong, J. (2015) 'An Empirical Study on Impact Factors of Faculty Remuneration Across 18 Higher Education Systems'. In: U., Teichler and W. K., Cummings (eds.) Forming, Recruiting and Managing the Academic Profession, pp. 163-186. Dordrecht: Springer.

Stensaker, B., Välimaa, J. and Sarrico, C. S. (eds.) (2012) Managing Reform in Universities. The Dynamics of Culture, Identity and Organizational Change. New York: Palgrave.

Stephan, P. E. (1996) 'The Economics of Science', Journal of Economic Literature, 34/3: 1199-235.

- (2010) 'The Economics of Science - Funding for Research', International Centre for Economic Research Working Paper, 12.

_ (2012) 'Pay Inequality Makes for Better Science', Scientific American Magazine, 307/4:

— Importance of Age, Place, and Time. Oxford: Oxford University Press.

Stern, S. (2004) 'Do Scientists Pay to Be Scientists?', Management Science, 50/ 6: 835-53.

Teichler, U. (1996) 'Comparative Higher Education: Potentials and Limits', Higher Education, 32: 431-65.

— and Höhle, E. A. (eds.) (2013) The Work Situation of the Academic Profession in Europe: Findings of a Survey in Twelve Countries. Dordrecht: Springer.

- Arimoto, A., and Cummings, W. K. (2013) The Changing Academic Profession. Major Findings of a Comparative Survey. Dordrecht: Springer.

Thursby, M., Thursby, J. and Gupta-Mukherjee, S. (2007) 'Are There Real Effects of Licensing on Academic Research? A Lifecycle View', Journal of Economic Behavior \& Organization, 63: 577-98.

Toutkoushian, R. K., Bellas, M. L. and Moore, J. V. (2007) 'The Interaction Effects of Gender, Race, and Marital Status on Faculty Salaries', The Journal of Higher Education, 78/5: 572-601.

- and Paulsen, M. B. (2016) Economics of Higher Education. Background, Concepts, and Applications. Dordrecht: Springer.

Ward, M. (2001) 'The Gender Salary Gap in British Academia', Applied Economics, 33/13: 1669-81.

Ward, M. E., and Sloane, P. J. (2000) 'Non-pecuniary Advantages Versus Pecuniary Disadvantages: Job Satisfaction among Male and Female Academics in Scottish Universities', Scottish Journal of Political Economy, 47/3: 273-303.

Williams, G., Blackstone, T., and Metcalf, D. (1974) The Academic Labour Market: Economic and Social Aspects of a Profession. New York: Elsevier. 